\title{
Herramienta para la educación inclusiva en estudiantes con discapacidad auditiva en la pandemia del Covid 19
}

\section{Tool for inclusive education in students with Hearing loss in the Covid 19 pandemic}

\author{
SUÁREZ, Sir A. ${ }^{1}$ \\ Resumen \\ Los obstáculos causados por el COVID-19 en la educación, han afectado la formación de estudiantes \\ con discapacidad auditiva. Se presenta una herramienta virtual que puede ser incorporada como \\ medio de enseñanza en clases no presenciales, y que tiene como finalidad la traducción de textos \\ académicos a lenguaje de señas colombianas. La tasa de acierto de traducción es del 88,76\% y, se \\ destaca por la facilidad e incorporación a los materiales de enseñanza. \\ Palabras clave: Discapacidad auditiva, COVID-19, lenguaje de señas.
}

\begin{abstract}
The obstacles caused by COVID-19 in education have affected the training of students with Hearing loss. A virtual tool is presented that can be incorporated as a means of teaching in non-face-to-face classes, and whose purpose is the translation of academic texts into Colombian sign language. The translation success rate is $\mathbf{8 8 . 7 6 \%}$ and stands out for its ease and incorporation into teaching materials.
\end{abstract}

key words: Hearing loss, COVID-19, sign language.

\section{Introducción}

El acceso a la educación es un reto a nivel global, determinado por diferentes causas, tales como el estrato económico, zona de ubicación, calidad de la educación adquirida en años anteriores, restricción de cupos para el acceso a la educación, entre otros. Son condiciones que al final terminan afectando el ingreso a un programa o ciclo académico. Si a estas causas agregamos las pocas posibilidades y herramientas que existen para las personas que tienen una condición de discapacidad, se terminaría completando un ciclo donde las posibilidades son muy bajas para estos estudiantes, ya sea para su ingreso o permanencia.

Las personas con discapacidad tienen barreras dadas por su entorno, las cuales impiden el acceso a la educación, al no contar con herramientas adecuadas para la adquisición del conocimiento, y su concepto implica que de una manera plena y con condiciones de igualdad puedan acceder a todos los bienes y servicios (ONU, 2006).

En Colombia la Fundación Saldarriaga Concha mantiene el Índice Multidimensional de Inclusión Social y Productiva de las personas con discapacidad, el cual permite conocer el nivel de inclusión social e inclusión

\footnotetext{
${ }^{1}$ Docente. Facultad de Ingeniería. Programa Ingenieria de Sistemas. Universidad Francisco de Paula Santander Ocaña. Grupo de Investigación Grucite. sasuarezc@ufpso.edu.co
} 
productiva (FSC, 2020), ubicando al departamento Norte de Santander en el puesto 12, con una inclusión del $36 \%$ y doble exclusión del $29 \%$; los resultados permiten conocer que las personas del departamento, poseen menores condiciones de inclusión que las del resto a nivel nacional (FSC, 2018); el componente de inclusión comprende 3 dimensiones: educación, servicios de salud, vivienda y servicios públicos.

El enfoque basado en el componente de dimensión educativo permite evaluar la inclusión y acceso a los ciclos educativos, pero esa inclusión puede convertirse en deserción, al no existir herramientas flexibles y eficientes para la comunicación entre docente y estudiante, partiendo de la base de los tipos de discapacidad y su división de acuerdo con deficiencias físicas, sensoriales y mentales.

Todos estos obstáculos se han incrementado con la aparición del COVID-19 como enfermedad infecciosa causada por el nuevo coronavirus, descubierto en la ciudad de Wuhan (China) y como tal informado a la Organización Mundial de la Salud (OMS) el 31 de diciembre de 2019, y luego de varios meses todos los países tuvieron que tomar medidas que impidieran la rápida propagación de la enfermedad. Las cifras globales para el mes de septiembre de 2020 afectan a 177 países y arrojan un total de 31.944.038 de contagiados, los cuales en Colombia llegan a 782.695 (University Johns Hopkins, 2020).

Debido a la rápida expansión y la facilidad en los contagios el gobierno nacional debió expedir el decreto 457 (Ministerio del Interior, 2020) como aislamiento preventivo obligatorio desde el 25 de marzo hasta el 13 de abril de 2020 garantizando el derecho a la vida y la salud, desde esa fecha el Gobierno Nacional, se vio obligado a prorrogar el aislamiento en repetidas ocasiones debido al incremento de los casos. Partiendo de la base de ese decreto, el Ministerio de Educación también publicó dentro de sus normativas el Decreto 660 (Ministerio de Educación Nacional, 2020) donde se dictan medidas relacionadas con el calendario académico. Después de una medición del trabajo académico en casa, se pudo conocer el porcentaje y materiales utilizados para seguir impartiendo las clases, dentro de las cuales las herramientas de apoyo académico con material impreso ocupan un $58 \%$, apoyo de programas de radio y televisión un $23.2 \%$, y el $21.1 \%$ con apoyo de plataformas digitales. Sin embargo, no hay estadísticas precisas sobre las personas con discapacidad y su entorno de aprendizaje, ni las herramientas de apoyo académico centradas en esta población.

Este artículo se centra en los estudiantes con discapacidad, y concretamente del tipo sensorial, aquellas personas con discapacidad auditiva en Colombia, donde el Instituto Nacional para Sordos (INSOR) tiene como objetivo promover desde el sector educativo la implementación de una política pública para la inclusión de las personas con discapacidad auditiva (INSOR, 2020), que intenta minimizar la brecha educativa generada por el COVID-19, contando con recursos educativos clasificados en: Módulos, repositorios de clase, datos curiosos, Literatura, Saber 11 y diccionario de lengua de señas colombiana (LSC). Todos estos contenidos inclusivos se encuentran en el portal del instituto, y son denominados herramientas TIC para aprender en tiempos de quedarse en casa y prevenir el contagio del COVID-19, pero son contenidos que no pueden ser modificados o moldeables al mensaje que se pretende dar, es por ello la necesidad de una herramienta más flexible.

El departamento Norte de Santander, ubicado al oriente colombiano, cuenta con 3 universidades públicas, que brindan el acceso a la educación superior, es por ello que la inserción, aprendizaje y deserción de estudiantes con discapacidad auditiva toma un valor muy importante, más ahora cuando la comunicación se debe hacer de forma virtual. El problema radica en el conocimiento de la lengua de señas por parte del docente, quien se encuentra en una encrucijada que lo lleva a tomar diferentes métodos, para poder transmitir el conocimiento y la mayoría nunca ha tenido contacto con la lengua, ni con estudiantes con esta discapacidad, además las instituciones no cuenta con personal capacitado que pueda ser un intermediario para compartir la información y realizar una interpretación o traducción entre la lengua escrita y la lengua de señas. 
Dentro de las herramientas virtuales se pueden destacar Visicast (Elliott, Glauert, Kennaway, \& Marshall, 2000). Esta herramienta muestra por medio de un humanoide la información en centros de atención al público, su funcionamiento se origina al tomar el movimiento de un humano; aunque hace que sea más rápida la creación de bibliotecas, también presenta un inconveniente debido a que la persona debe conocer el lenguaje de señas, sin embargo es una excelente perspectiva interdisciplinaria para el reconocimiento de señas (Bragg, y otros, 2019).

Signame es una aplicación que ofrece información sobre bibliotecas y museos para personas sordas mediante videos y captura de personas; Foresign es la aplicación que ayuda a la integración de personas inmigrantes con lengua de signos española y el sistema de signos internacional (CNSE, 2018). Las anteriores herramientas son bastante restrictivas y no ofrecen signos en la lengua colombiana (LSC).

Ubicándonos en el contexto colombiano se encuentra el sistema traductor de lengua de señas a texto basado en FPGA el cual logra reconocer 23 señas estáticas con un acierto del 98.15\% (Guerrero y Pérez, 2015). Mientras que la propuesta para minimizar las barreras desarrollada mediante un intérprete virtual es una herramienta bastante útil con más de 3000 imágenes y 13 movimientos, sin embargo no presenta una colección de las traducciones que puede realizar (Pérez, Duque, y Guerra, 2016).

Ahora bien, en el trabajo titulado Recurso educativo web para la enseñanza de lengua de señas colombiana se realiza una implementación más extensa y se enfatiza que se puede adquirir nociones básicas de LSC, las personas con discapacidad o las personas oyentes (Arroyave, Hernández, Pérez, y Duque, 2016). Un aplicativo web muestra los conceptos de 5 categorías resaltando los números y el alfabeto, permitiendo la asimilación de diferentes contextos, el cual contiene una colección más extensa, pero no determina si se puede exportar una frase, al unir diferentes conceptos o visualizar frases que no se incluyan en la colección (Duque-Méndez y Hernández-Leal, 2018).

Tomando en cuenta lo anterior se presenta una herramienta virtual que puede ser utilizada por docentes para incluir LSC en sus comunicaciones, ya sea diapositivas o documentos textuales, dando la oportunidad al mismo docente de generar las señas de manera automática, y sin conocimiento del lenguaje de señas, lo que facilita la comunicación en situaciones de aislamiento preventivo generado por el COVID-19.

\section{Metodología}

Se utiliza una metodología cascada (Royce, 1987), (Pressman, 1993), la cual comprende la etapa de análisis, diseño, codificación, pruebas y verificación; esta metodología se basa fundamentalmente en un modelo lineal donde cada etapa es revisada de forma exhaustiva antes de continuar con la siguiente fase. En el análisis se realiza la especificación de requisitos del software, en la codificación se utiliza Matlab (Ploskas \& Samaras, 2016) el cual permite trabajar sobre celdas de matrices, permitiendo realizar cálculos numéricos necesarios para el procesamiento de imágenes, las pruebas se realizan sobre material académico y la verificación es el resultado del análisis de cada seña generada.

Desde el punto de vista del diseño de la aplicación se realiza una investigación experimental, que permite conocer la causa del efecto en la educación y, cuyo propósito es una investigación aplicada para la resolución de problemas prácticos. La población y la muestra están enfocadas en el desarrollo y prueba del software, el cual cuenta con una colección de 97 palabras y mantiene 240 sinónimos, permitiendo un total de visualización de 337 palabras, con las cuales se puede formar una cantidad considerable de frases. Los tests de satisfacción se realizaron con 4 docentes de la Universidad Francisco de Paula Santander Ocaña y la Universidad de Pamplona en el área de ingeniería, y las pruebas de traducción basada en materiales académicos de 3 asignaturas, seleccionando una muestra aleatoria de 18 diapositivas las cuales contenían 932 palabras textuales para traducir 
a LSC. La tasa de acierto se calcula sobre cada diapositiva, debido a su interdisciplinariedad, para concluir con una tasa de acierto global. Es por eso que la tasa de éxito de la herramienta presenta dos medidas diferentes: la primera fue basada sobre el docente con preguntas generales para conocer la satisfacción, mientras que la segunda es estricta en cuanto a la forma como una palabra es traducida correctamente al LSC.

\section{Resultados}

Los resultados se clasifican en la necesidad de la herramienta, el uso e incorporación en el material del docente y la prueba final por parte del experto en lengua de señas, como sistema a utilizar en el aislamiento preventivo generado por el COVID-19.

\subsection{Diseño asistente virtual}

El asistente virtual se realizó utilizando una plantilla en Matlab donde se determina la ubicación de los videos, botones y cuadro de texto, para ello se realizaron un total de 5 prototipos, de los cuales se seleccionó el que ofrecía una mayor organización de los paneles de control. La Figura 1 muestra la incorporación de botones permitiendo un acceso rápido a las funciones.

Figura 1

Plantilla base en Matlab

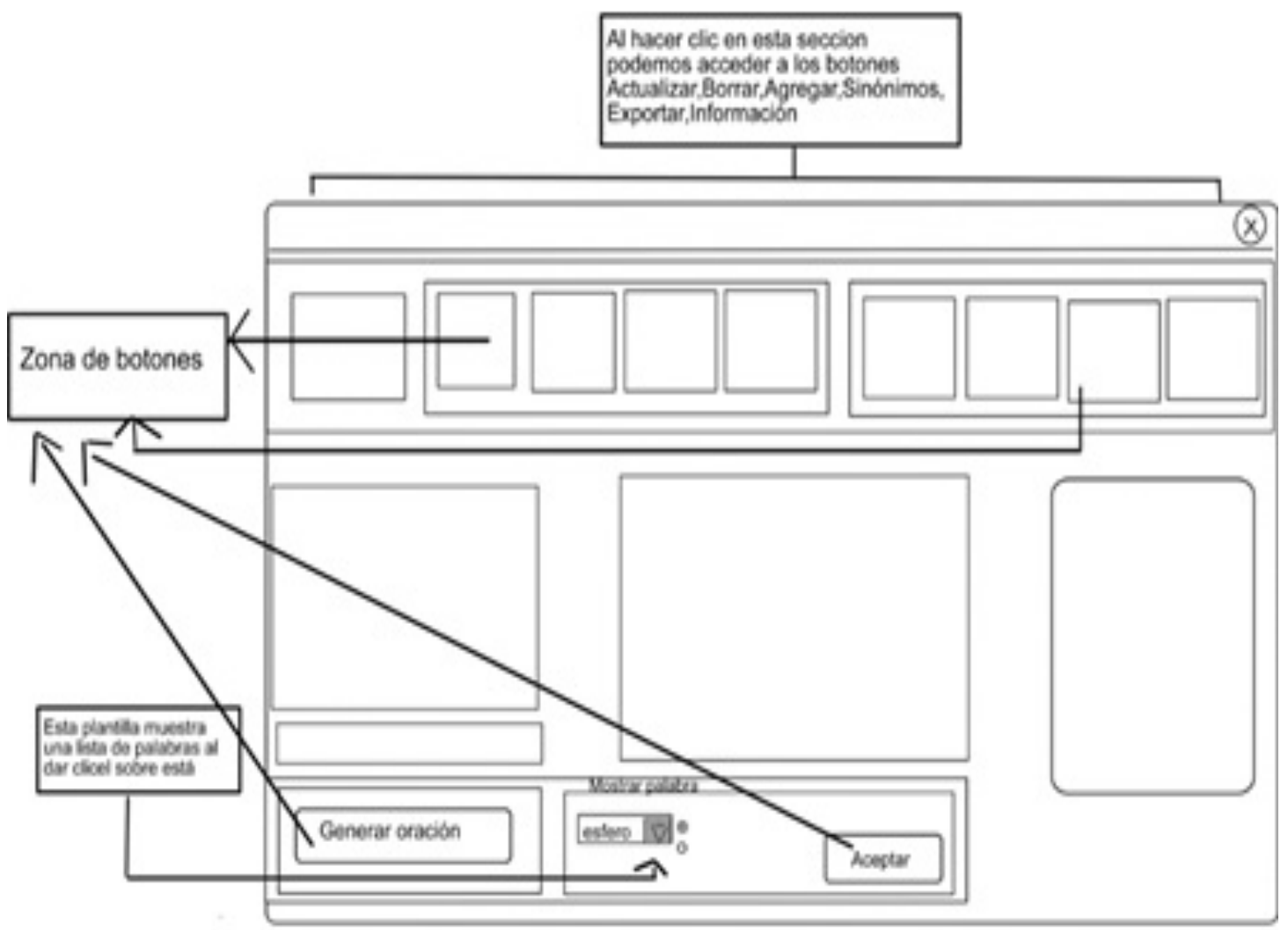

Fuente: elaboración propia

Esto permite que el software sea casi intuitivo, debido a que el docente solo tiene que utilizar los botones y su significado, para generar los videos que servirán como herramienta para la traducción de sus textos a LSC. Dentro de las funcionalidades se encuentra:

a. Panel de señas: permite borrar, agregar y actualizar la seña a formato Avi. 
b. Panel de sinónimos: permite agregar, borrar y mostrar la lista de sinónimos de cada palabra, este panel se encuentran las palabras almacenadas de tal forma que primero recurre a esta función, antes de deletrear una palabra que no se encuentre almacenada.

c. Panel de generación: tomando el texto ingresado en la ventana y analiza la matriz de celda para la generación de la seña.

d. Panel de mostrar palabra: genera el video con la LSC solicitada, ya sea completa o deletreada.

En la figura 2 se observa finalmente la implementación del diseño y puesta a punto de la herramienta, donde se observan de forma directa las diferentes funciones para una ágil traducción.

Figura 2

Presentación final de los paneles de control

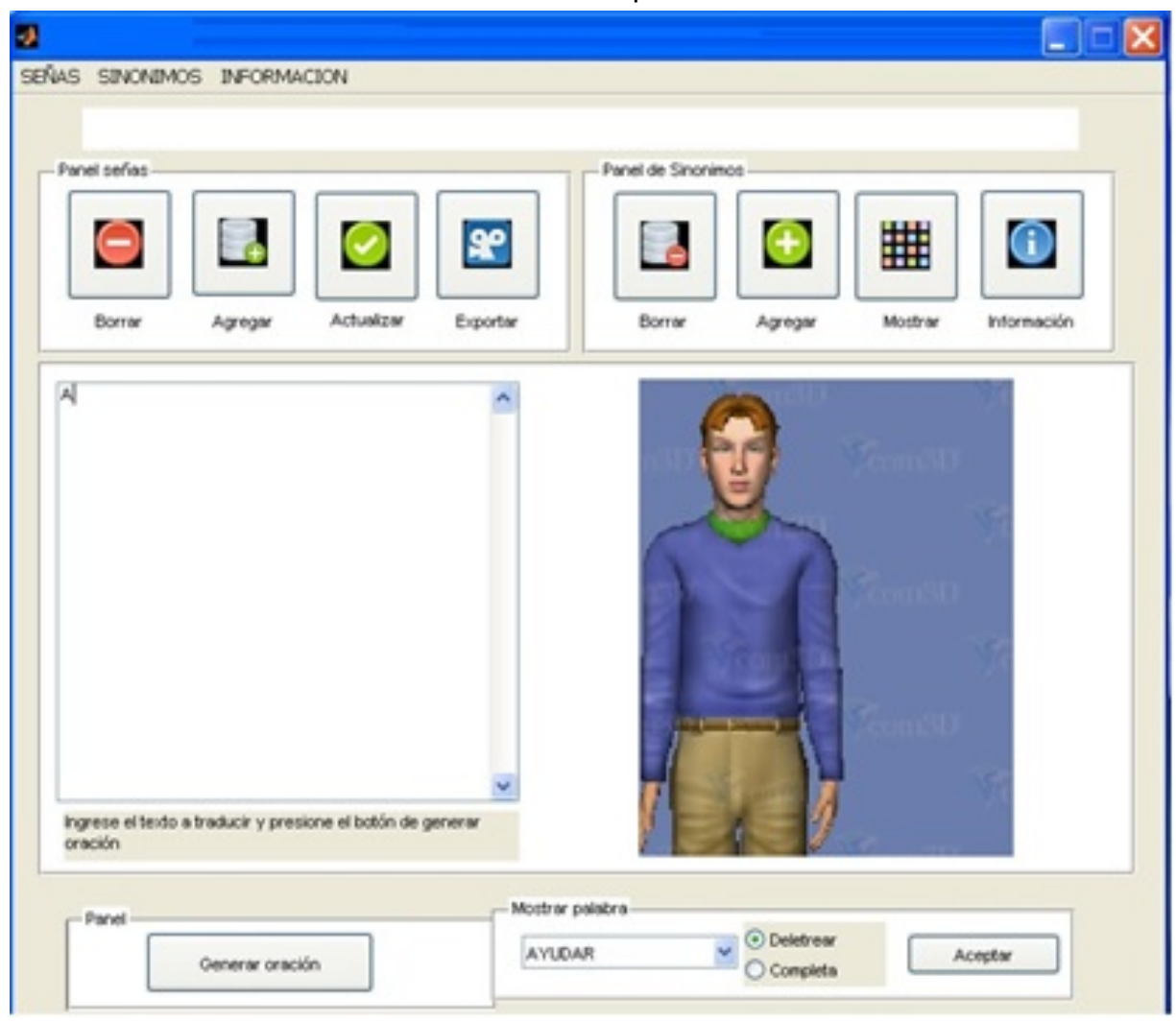

Fuente: elaboración propia

\subsection{Generación del alfabeto dactilológico}

Para construir el alfabeto dactilológico se utilizó una matriz de celdas las cuales almacenan una cantidad variable de imágenes en cada una, y corresponde a un caracter o palabra del alfabeto. La función de esta matriz es de suma importancia, ya que permite generar un video con los movimientos necesarios para la traducción de palabras de texto a LSC, manteniendo el orden de la representación y aumentando el tiempo de proceso.

En el cuadro 1 se puede ver una estructura de matrices de celda, donde una palabra puede tener distintos movimientos los cuales varían en longitud unos de otros; es por eso que cada celda puede almacenar un tipo de datos diferentes, dimensión y peso de la imagen, diferenciando a sistemas realizados con matrices básicas. El alfabeto LSC de la figura 3 consta de 27 señas las cuales fueron almacenadas en igual cantidad de celdas. La función principal de esta primera colección no es mostrar una letra, vas más allá, pues permite crear frases completas utilizando un constructor de frases, para cualquier palabra que no se encuentre en el diccionario, volviendo la colección más amplia. 
Cuadro 1

Construcción de una matriz de celdas

\begin{tabular}{|c|c|c|c|c|c|}
\hline \multicolumn{3}{|l|}{ Palabra 1} & Palabra 2 & \multicolumn{2}{|l|}{ Palabra 3} \\
\hline Im,1,1 & \multicolumn{2}{|c|}{ Im,1,2 } & & Im,1 & $\mathrm{Im}, 1,2$ \\
\hline \multirow[t]{3}{*}{ Im,2,1 } & \multicolumn{2}{|c|}{$\operatorname{Im}, 2,2$} & & $\operatorname{Im}, 2,1$ & Im,2,2 \\
\hline & & & $\operatorname{Im}, 4$ & $\operatorname{Im}, 3,1$ & $\operatorname{Im}, 3,2$ \\
\hline & & & $\operatorname{Im}, 5$ & & \\
\hline Palabra 4 & & & Palabra 5 & Palabra 6 & \\
\hline Im,1 & Im,1,2 & $\mathrm{Im}, 1,3$ & Im,1 & Im,1 & \\
\hline $\operatorname{Im}, 2,1$ & $\operatorname{Im}, 2,2$ & $\mathrm{Im}, 2,3$ & $\mathrm{Im}, 2$ & & \\
\hline $\mathrm{Im}, 3,1$ & $\operatorname{Im}, 3,2$ & Im,3,3 & & & \\
\hline
\end{tabular}

Fuente: elaboración propia

Figura 3

Nombre de la figura 


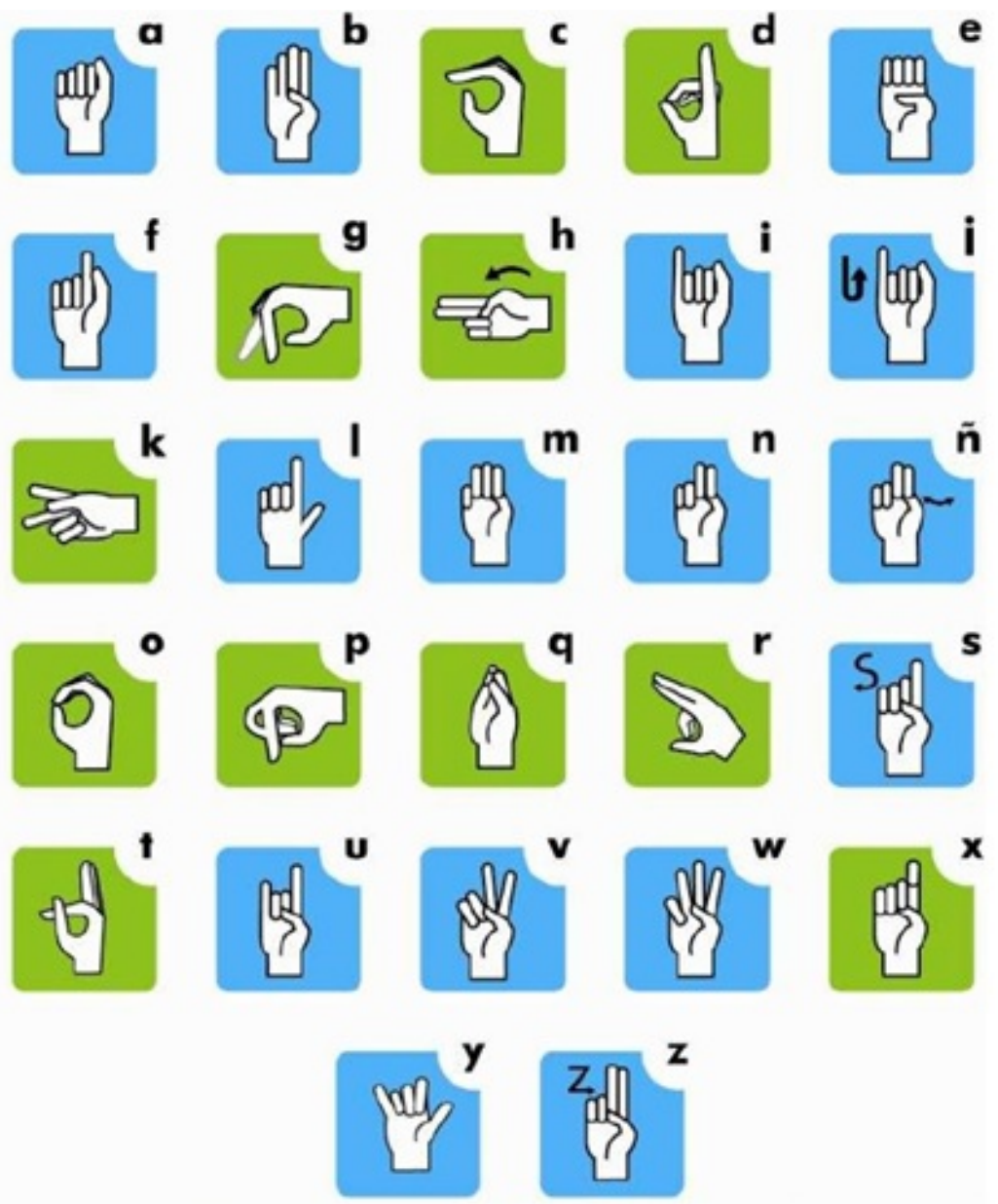

Fuente: (Mejía Cheng y Correa Cadavid, 2010)

\subsection{Asistente virtual de presentaciones}

Cuando se deletrea, el sistema realiza una concatenación de cada una de las celdas formando una nueva matriz de celdas de la palabra deseada, la cual, tiene un formato formado por la cantidad de letras a mostrar de la palabra y en cada columna una letra, las cuales permitirán enlazar con la imagen de la colección. En el Cuadro 2 podemos ver como la palabra "ADIOS" está compuesta por 7 campos, donde el primero almacena la cantidad de caracteres, el segundo la dirección del video de la palabra y, los otros 5 están compuestos por cada uno de los caracteres de la palabra con sus respectivos videos, los cuales se concatenan para formar un solo video del ejemplo "ADIOS".

\section{Cuadro 2}

Matriz de celdas de imágenes

\begin{tabular}{|c|c|c|c|c|c|c|}
\hline I & Palabra & C1 & LC2 & C3 & C4 & C5 \\
\hline 5 & Adios & A & D & I & O & S \\
\hline 11 & Bienvenidos & B & I & E & N & $\ldots$ \\
\hline 1 & 9 & 9 & & & & \\
\hline 2 & 23 & 2 & 2 & & & \\
\hline. & $\ldots$ &. &. &. &. &. \\
\hline
\end{tabular}

Fuente: elaboración propia

El software cuenta con una colección de 97 palabras y mantiene 240 sinónimos, permitiendo un total de visualización de 337 palabras con las cuales se puede formar una cantidad considerable de frases. 
Las imágenes cargadas en la matriz de celdas aceleran la visualización, pero también pueden ser extraídas como imágenes animadas. La manera como muestra las imágenes es transparente para el usuario, el cual solo observa el video con la seña, sin conocer la forma de concatenación de las imágenes. Si solicita una traducción ingresada en la caja de texto de "algunos estudiantes", la transición estará compuesta por las imágenes almacenadas en la matriz de celdas, tal como lo muestra la Figura 4. La velocidad de procesamiento y correlación de cada pixel de todas las imágenes, hace que se forme una sola imagen en movimiento, transformándose en un video que contiene una palabra en LSC.

Figura 4

Procesamiento y transición de una frase al LSC

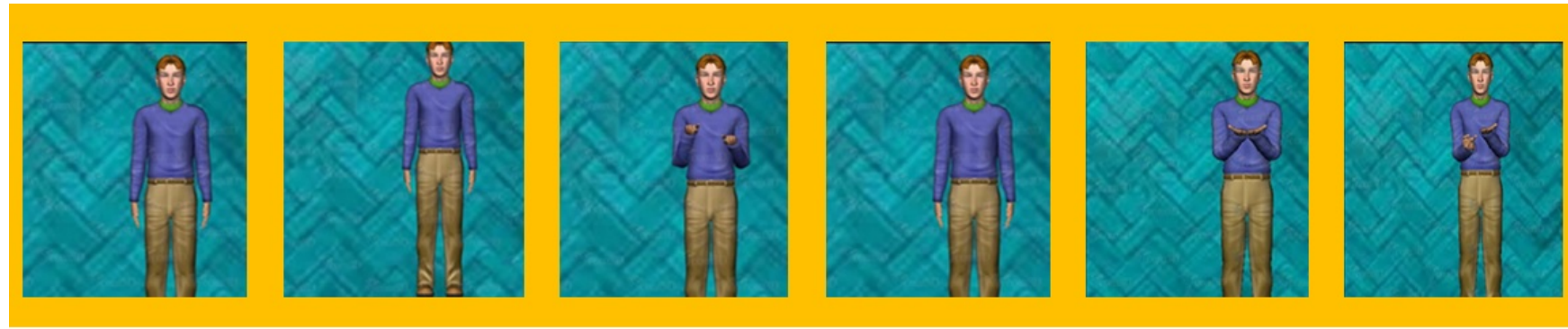

Fuente: elaboración propia

En la Figura 5 se muestra la secuencia de generación de frases a señas, donde el docente y el estudiante tienen las mismas funcionalidades ya que puede ser utilizado en ambas direcciones, de oyente a receptor y de receptor a oyente.

Figura 5

Video LSC bidireccional oyente - receptor

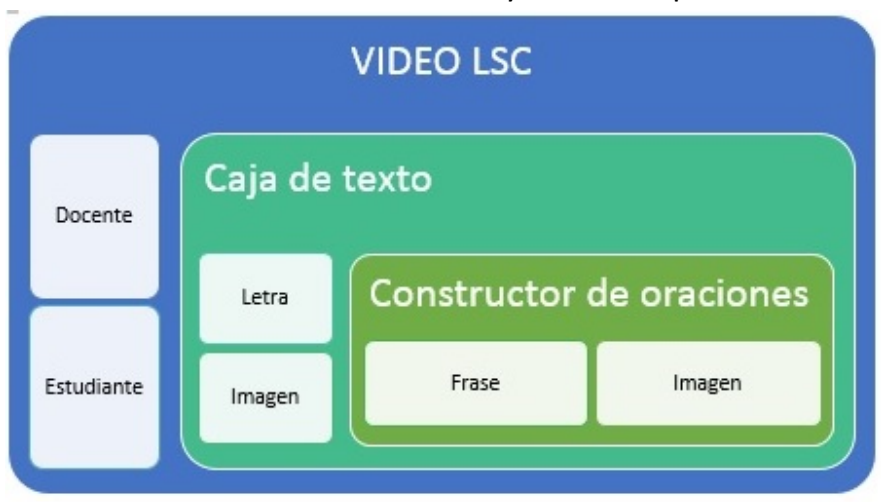

Fuente: elaboración propia

No sería conveniente obtener una muestra con métricas de medición de software, ni tampoco sería efectivo sobre las funcionalidad que pueda encontrar el docente, $y$ antes de hacer las pruebas finales con estudiantes con problemas auditivos es más efectivo hacer pruebas de traducción de texto a LSC, supervisadas por el experto en señas, el cual da un porcentaje acertado de funcionalidad de la herramienta. Pero para destacar la encuesta realizada a los 4 docentes con puntuaciones de 1 a 4, los cuales van desde muy baja, baja, media y alta, basada en 4 preguntas: facilidad de instalación con puntaje alto, Funcionalidad puntaje alto, usabilidad con puntaje medio y fiabilidad puntaje alto. 
A continuación se muestran los resultados obtenidos de la traducción de texto a LSC. La tasa de éxito en la traducción a lenguaje de señas se realizó con una muestra de 18 diapositivas, extraídas al azar de presentaciones de 3 asignaturas, en el cuadro 3 se muestra la cantidad de palabras extraídas de cada diapositiva.

Cuadro 3

Cantidad de palabras por diapositiva

\begin{tabular}{|l|l|l|l|l|l|}
\hline D1 & D2 & D3 & D4 & D5 & D6 \\
\hline 4 & 64 & 20 & 52 & 59 & 80 \\
\hline D7 & D8 & D9 & D10 & D11 & D12 \\
\hline 91 & 55 & 33 & 61 & 44 & 47 \\
\hline D13 & D14 & D15 & D16 & D17 & D18 \\
\hline 97 & 39 & 39 & 25 & 77 & 45 \\
\hline
\end{tabular}

Fuente: elaboración propia

El porcentaje de acierto en cada diapositiva se midió sobre el 100 por ciento de las palabras que forman cada una de las presentaciones y no sobre el total de palabras de todas las diapositivas. Y el acierto total de la prueba fue el promedio del acierto de la sumatoria de todas las diapositivas dividida entre la cantidad de diapositivas.

Al analizar la cantidad de palabras acertadas por diapositiva se pueden encontrar rangos comprendidos entre $42,55 \%$ y $100 \%$. Es importante resaltar que la diapositiva número 12 fue la que obtuvo el menor porcentaje de acierto con 42,55\%, y la cual contenía 47 palabras (ver Gráfico 1), esto se debe principalmente a que estaba formada por operadores aritméticos, lógicos y de relación propios de un lenguaje de programación los cuales no son de uso familiar en habla de señas, pero pueden ser deletreados para subir la tasa de acierto. Al analizar los mayores porcentajes de acierto como la diapositiva 1 y 18 , nos encontramos que son diapositivas de bienvenida a la unidad y de finalización de la unidad con lo cual están más familiarizados en el contexto de LSC.

Gráfico 1

Porcentaje de acierto por diapositiva

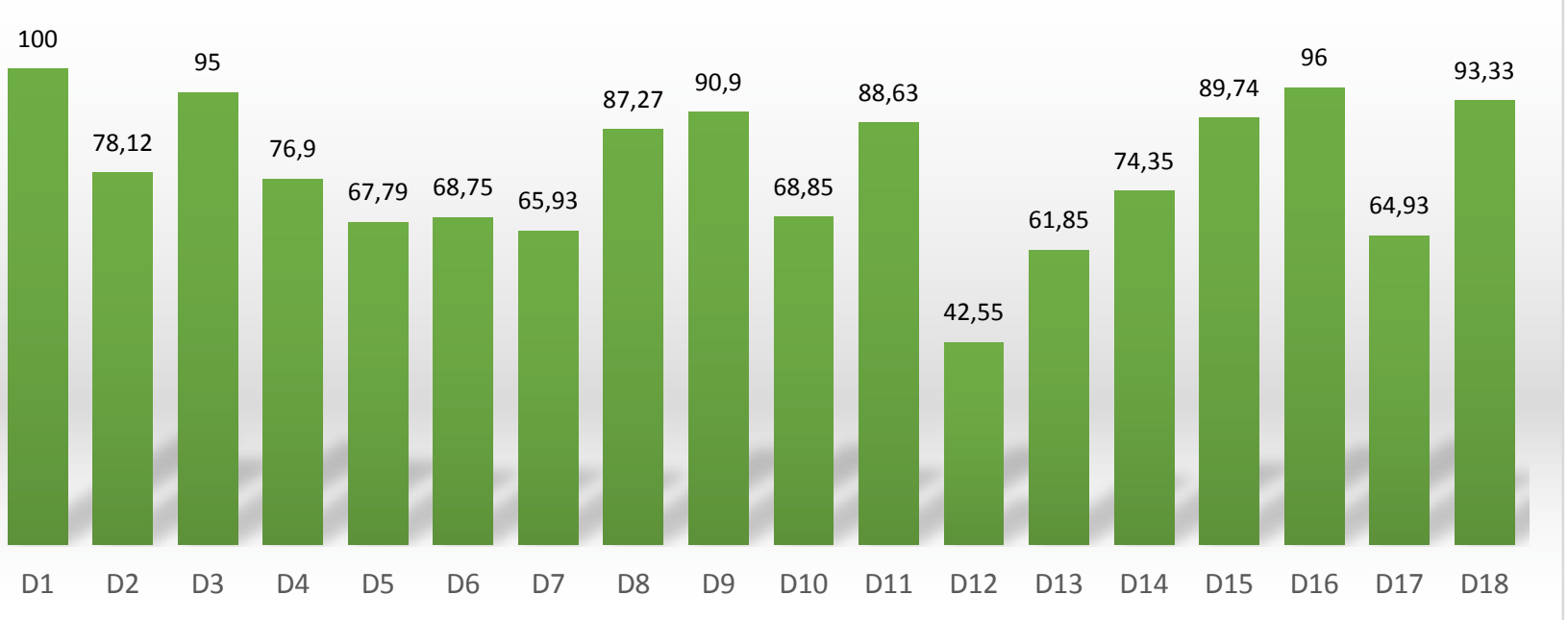

Fuente: elaboración propia 
El porcentaje de acierto total en la traducción a lenguaje de señas fue de un 78,38\%, el cual puede aumentar la tasa de éxito al deletrear las palabras no incorporadas en la colección, con lo cual tuvo una mejoría del 88,76\%, pero aumentando también el tiempo y peso del video, así como de la preparación del texto para su explicación.

La forma de utilizar la herramienta una vez traducida la palabra ingresada a LSC, es guardando el video, y luego puede ser incorporado al material académico a través de la inserción de objetos o videos, disponibles en cualquier aplicación como PowerPoint, Word, Excel, etc. En la Figura 6 se observa la incorporación del video LSC en la diapositiva, traduciendo todo el texto de la presentación.

Figura 6

Diapositiva con traducción de texto a LSC mediante la herramienta

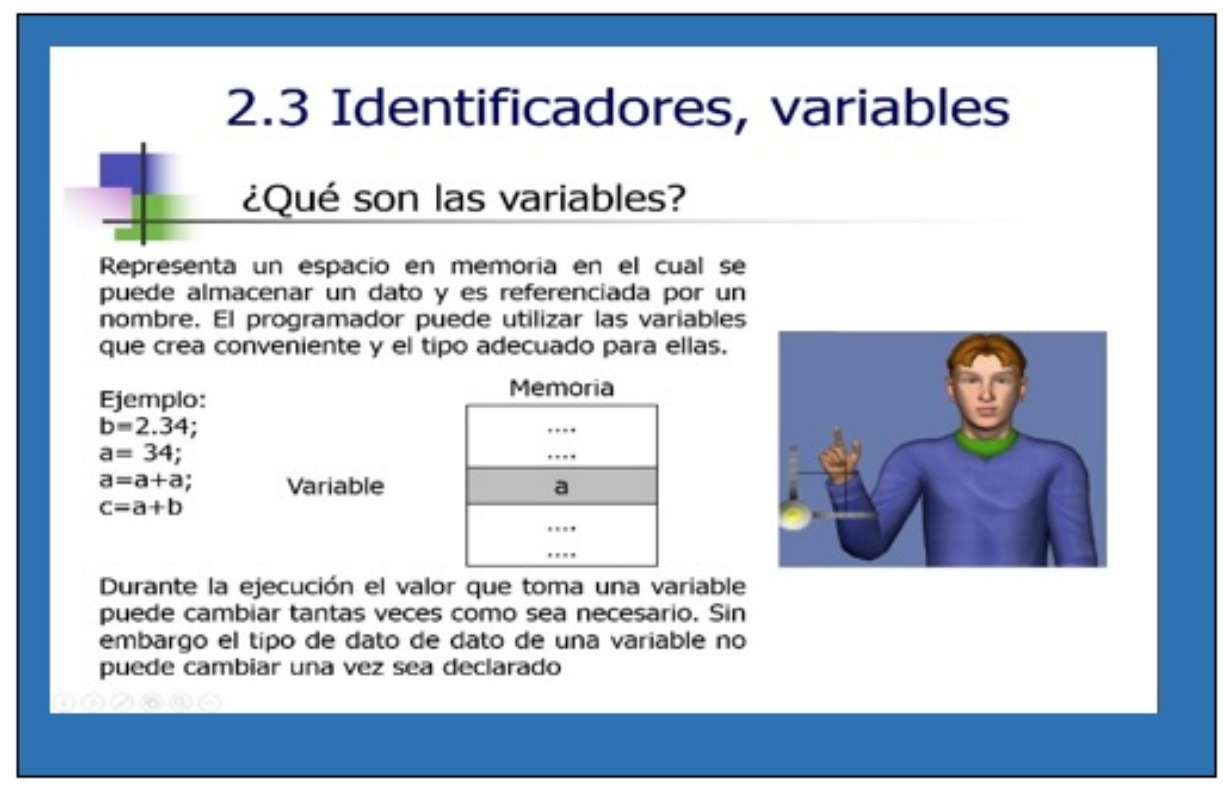

Fuente: elaboración propia

Igualmente, si realizamos un análisis radial se puede encontrar que cuando más retirados estén los puntos del centro, la traducción a lenguaje de señas aumenta, lo cual representa una buena progresión basada en la interdisciplinariedad de cada diapositiva, sin encontrar casi valores atípicos, ver Gráfico 2.

\section{Gráfico 2}

Analisis radial 


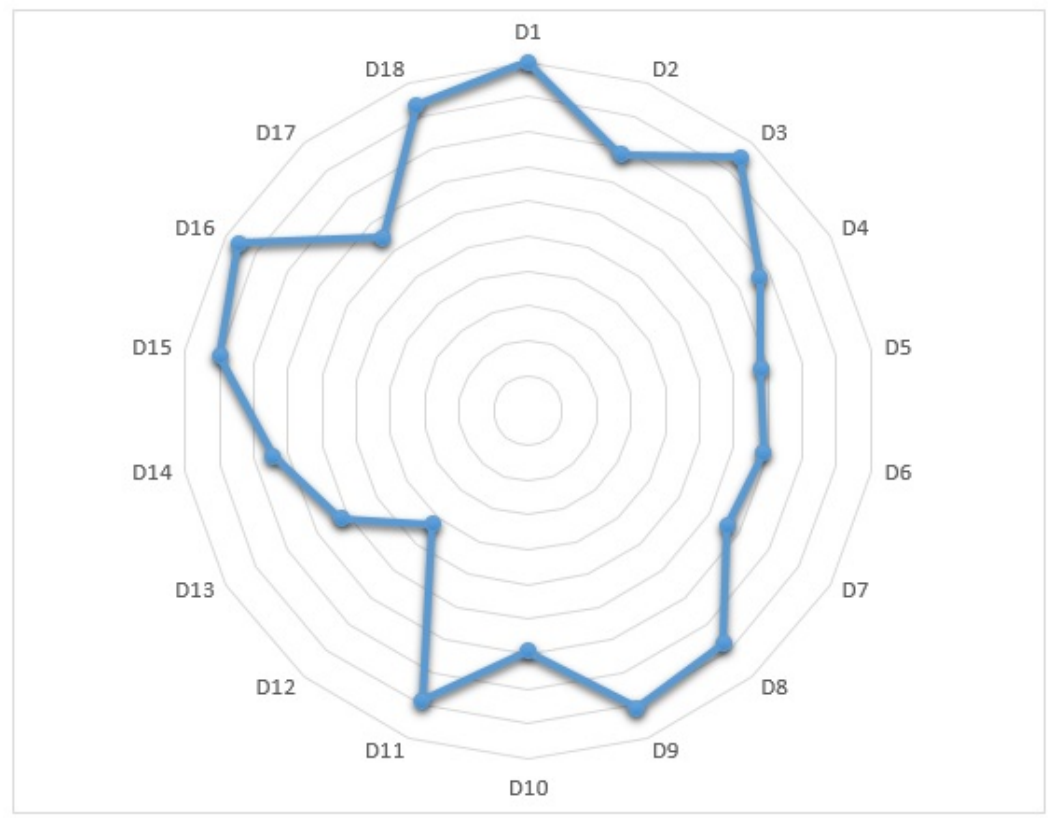

Fuente: elaboración propia

\section{Conclusiones}

La herramienta virtual para la enseñanza basada el procesamiento de imágenes, compuesto por la lengua de señas colombiana, puede ser incorporada a cualquier tipo de presentación. Los resultados permiten realizar una traducción eficiente, superando un $80 \%$ la tasa de acierto, esto permite evidenciar la fiabilidad de manejo de la herramienta, la cual puede ser utilizada en situaciones de aislamiento, destacando la facilidad de uso por parte del docente o estudiante. Para trabajos futuros se espera la incorporación de nuevas palabras a la colección que aumenten la efectividad de traducción. Finalmente, con el asistente virtual se puede reducir la incorporación de intérpretes, los cuales no siempre están disponibles como interlocutores para llevar la información al estudiante.

\section{Referencias bibliográficas}

Arroyave, A. F., Hernández, E. J., Pérez Z, Ángela M., \& Duque M, N. D. (2016). Recurso educativo web para la enseñanza de lengua de señas colombiana. Ingeniería E Innovación, 4(2).

https://doi.org/10.21897/23460466.1178

Bragg, D., Koller, O., Bellard, M., Berke, L., Boudreault, P., Braffort, A., Caselli, N., Huenerfauth, M., Kacorri, H., Verhoef, T. Vogler, C., Morris, M. (2019). Sign Language Recognition, Generation, and Translation: An Interdisciplinary Perspective. doi:10.1145/3308561.3353774

CNSE, Confederación Estatal de Personas Sordas (2018). Estudio sobre la realidad de las personas sordas inmigrantes. Madrid: CNSE.

Duque-Méndez, N. D. y Hernández-Leal, E. J. (2018). Web application for the learning of Colombian Sign.

Elliott, R., Glauert, J., Kennaway, R., y Marshall, I. (2000). The development of language processing support for the ViSiCAST project. doi:10.1145/354324.354349

FSC (2018). Índice multidimensional de inclusión social y productiva para personas con discapacidad resultados Norte de Santander. Fundación Saldarriaga Cocha. Bogotá - Colombia: Fundación Saldarriaga Cocha. 
FSC (23 de agosto de 2020). Fundación Saldarriaga Concha. Obtenido de https://www.saldarriagaconcha.org/indice-personas-discapacidad/que-es/.

Guerrero, J., y Pérez, W. (2015). Sistema traductor de la lengua de señas colombiana a texto basado en FPGA. DYNA, 82, 172-181. doi:10.15446/dyna.v82n189.43075

INSOR (19 de septiembre de 2020). Obtenido de http://www.insor.gov.co/home/entidad/obietvos-yfunciones/

INSOR (7 de 2020). Misión y Visión. Bogotá: Instituto Nacional para Sordos. Obtenido de http://www.insor.gov.co/home/entidad/objetivos-y-funciones/

Mejía, L., y Correa, C. (2010). Diseño de un manual de estilo gráfico para la publicación "Lengua de Señas Colombiana" para el uso y aprendizaje de la comunidad discapacitada auditiva de Santiago de Cali (Tesis de grado). Universidad Autónoma de Occidente.

Ministerio de Educación Nacional (13 de Mayo de 2020). Decreto Legislativo 660 . Bogotá, Colombia.

Ministerio del Interior (2020). Por el cual se imparten instrucciones en virtud de la emergencia sanitaria generada por la pandemia del coronavirus COVID-2019 y el mantenimiento de orden público. Decreto número 457. Bogotá.

ONU (2006). Convención sobre los derechos de las personas con discapacidad.

Pérez, Á. M., Duque, N., y Guerra, A. (2016). Intérprete virtual de lengua de señas colombiana. Ingeniería e Innovación, 4.

Ploskas, N., y Samaras, N. (2016). GPU Programming in MATLAB.

Pressman, R. S. (1993). Ingeniería de Software: Un enfoque práctico. 3a edición. McGraw-. Hill.

Royce, W. W. (1987). Managing the development of large software systems: concepts and techniques. Proceedings of the 9th international conference on Software Engineering, (págs. 328-338).

University Johns Hopkins (9 de 2020). COVID-19 Dashboard by the Center for Systems Science.

Esta obra está bajo una Licencia Creative Commons Attribución-NoCommercial 4.0 International

(cc) BY-NC 